\title{
Aphanamixis Polystachya: A Potential Non-Edible Source of Biodiesel in Bangladesh
}

\author{
Kaniz Ferdous $^{1 *}$, Anjan Deb ${ }^{1}$, Jannatul Ferdous ${ }^{1}$, M. Rakib Uddin ${ }^{1}$, Maksudur R. Khan ${ }^{1,2}$, \\ M. A. Islam ${ }^{1}$ \\ ${ }^{1}$ Department of Chemical Engineering and Polymer Science; Shahjalal University of Science and Technology (SUST); \\ Sylhet 3114, Bangladesh; Tel: +880 (0) 1736144941, Fax: +880 (0)821 715257. \\ ${ }^{2}$ Faculty of Chemical and Natural Resources Engineering, University Malaysia Pahang, 26300 Gambang, Kuantan, \\ Pahang, Malaysia.
}

\begin{abstract}
This paper represents an attempt that was made to prepare Biodiesel from a non-edible source, Aphanamixis Polystachya (Pitraj). Oil was extracted from the seed by mechanical press method. Various properties of raw oil such as viscosity, Free Fatty Acid (FFA) content, specific gravity, saponofication value etc. were measured by standard methods. FFA content of raw oil was found higher, so the acid catalysed two step method, acid catalysed esterification followed by base catalysed transesterification, was studied. Various reaction parameters such as oil to methanol ratio, catalyst wt $\%$, reaction time and temperature were optimized for both esterification and transesterification reaction. ${ }^{1} \mathrm{H}$ NMR of prepared biodiesel and raw oil was studied which confirms the conversion of oil to biodiesel. Finally, the various properties of produced Biodiesel, such as viscosity, FFA, specific gravity, iodine value, cetane index, calorific value etc. were measured and compared with biodiesel and petro-diesel standards.
\end{abstract}

Keywords: pitraj, Aphanamixis Polystachya, biodiesel, esterification, transesterification.

\section{INTRODUCTION}

Ever-increasing price and diminution of conventional petroleum-derived fuels increases steadily the need for alternative fuels and therefore much effort has been devoted to their development. Biodiesel, an alternative diesel fuel, is made from renewable biological sources such as vegetable oils and animal fats. It is biodegradable, nontoxic, renewable, environmentally compassionate $[1,2]$, and its use in diesel engines also shows a decrease in the emission of $\mathrm{CO}, \mathrm{SOx}$, unburned hydrocarbons and particulate matter during the combustion process $[3,4]$.

The edible oils such as soybean oil in USA, rapeseed oil in Europe and palm oil in countries with tropical climate such as Malaysia are being used for the production of biodiesel to fuel their compression ignition engines [5]. In Bangladesh, the use of edible oils for engine fuel is not feasible since the potentiality of edible oil sources is below the annual demand [6]; however, there are several non-edible oilseed species such as Pitraj (Aphanamixis Polystachya), Nahor (Mesua ferrea.), Castor (Ricinus Communis L.), Karanja (Pongamia pinnata), Jatropha (Jatropha curcas), Neem (Azadirachta indica), Mahua (Madhuca indica), Simarouba (Simarouba indica) etc., which could be utilized for production of oil. Among these, pitraj is the oil seed bearing tree, which is nonedible and does not find any suitable application in our country. These seeds can be a potential source for biodiesel production in our country.
Base catalyzed transesterification reaction is widely used for biodiesel production from vegetable oil due to its faster kinetics than that of acid catalyzed process. But if FFA content in the oil is more than $2 \%$, the base catalyzed process is not feasible. The main problem for the non-edible oil sources is its high FFA content which limits the use of single step transesterification reaction. To overcome this problem two-step process were used to prepare biodiesel from different oils which have high content of FFA [7, 8]. In two-step process the first step is the acid catalyzed esterification, which reduces the FFA content of the oil and minimizes the soap formation in the second step (base catalyzed transesterification).

Since the FFA content of raw pithraj oil was higher, a two-step method was studied for the preparation of biodiesel. Various reaction parameters for esterification and transesterification reaction were optimized. Finally various properties of the produced biodiesel were measured and compared with one another and with biodiesel and petro-diesel standard.

\section{MATERIALS AND METHODS}

\subsection{Chemicals}

Methanol (99-100\%), ethanol (99-100\%), sodium hydroxide pellets $(96 \%)$, potassium hydroxide pellets (>84\%), phenolphthalein ( $\mathrm{pH} 8.2$ - 9.8), starch, acetone (99\%), n-Hexane(96\%), hydrochloric acid (37\%), isopropanol, iodine, sodium iodide, glacial acetic acid, bromine, carbon tetrachloride etc. were purchased from Merck, Germany. All the chemicals used were analytical reagent grade.

\footnotetext{
* Corresponding Author: Kaniz Ferdous, 


\subsection{Extraction of Oil}

Pithraj seeds were collected from road side of Sylhet region. Oil from the seed was extracted by mechanical press method. Mechanical press is vertical, manual operated, cylindrical $(4.3 \mathrm{~cm}$ ID) which have a spiral screw that convey the mass from the hopper to pressure raising area. Slow and continuous rotation of the mechanical press allows raising sufficient pressure for the extraction of oil. Here the spiral screw is used for random mixing, size distribution and passing the mass from hopper to pressure raising area. Oil drainage nozzles are located at the face of the expeller. Pressure raising area is located at the face of the expeller. In this expeller, pressure rises in slow and continuous rotation. The faster rotation of the expeller causes the back flow of the solid seed meal and it results the lowering of pressure. The input of seed grain should be controlled to prevent the loss of the seed because if the amount of raw seed is high, the extra seed meal stays within the screw and it is unable to reach in the pressure raising area. The back flow of seed grain should be adjusted with the rotation of the spiral screw. After oil extraction it was filtered. The oil was stored at room temperature.

\subsection{Preparation of Biodiesel}

In the current study biodiesel was prepared from pithraj oil by two-step method. A two-step method, acid catalyzed esterification followed by base catalyzed transesterification, of higher FFA containing oil (Pithraj oil) was adopted for the complete conversion of FFA and TG to fatty acid methyl esters. The first step (esterification) was carried out at $70^{\circ} \mathrm{C}$ and atmospheric pressure. Typically, $100 \mathrm{~mL}$ oil was taken in a threenecked $500 \mathrm{~mL}$ round bottomed flask equipped with a reflux condenser. The flask was placed on an electric heater with a temperature controller and magnetic stirrer. Sulfuric acid (5 wt $\%$ of oil) was mixed with required amount of methanol and transferred into the reaction medium. The reaction continued until the FFA of oil reduces below $2 \%$. After that the reaction contents were cooled to room temperature and reaction product was washed with hot water until clear water found. The organic phase was collected and dried under vacuum at $100^{\circ} \mathrm{C}$ for $30 \mathrm{~min}$. The dried sample $(50 \mathrm{~mL})$ was put into a three-necked $500 \mathrm{~mL}$ round bottomed flask, equipped with a reflux condenser, for base catalyzed transesterification. Sodium hydroxide pellets were mixed with required amount of methanol. Molar ratio of methanol to oil was taken excess for the total conversion of TG to biodiesel. The flask was placed on an electric heater with a temperature controller and magnetic stirrer. The transesterification reaction was performed under vigorous stirring at $60^{\circ} \mathrm{C}$. After a certain period reaction was stopped by adding stoichiometric amount of $\mathrm{HCl}$. Then contents were cooled to room temperature, and reaction product was washed with hot water until clear water found. The organic phase (biodiesel) was collected and dried under vacuum at $100^{\circ} \mathrm{C}$ for half an hour. Finally the various properties of the biodiesel were measured.

\subsection{Analytical Methods for Oil and Biodiesel}

FFA in the oil and biodiesel samples was analyzed by the method described in AOCS Aa 6-38. To determine FFA of sample, 4-5 gm of samples were dispersed in isopropanol $(75 \mathrm{~mL})$ and hexane $(15 \mathrm{~mL})$ followed by titration against $0.25 \mathrm{~N} \mathrm{NaOH}$ solution. Saponification value (SV) was determined by standard method [9]. Typically, $1 \mathrm{~g}$ sample was taken with $25 \mathrm{~mL}$ alcoholic $\mathrm{KOH}$ solution, heated for $1 \mathrm{hr}$ in a steam bath with occasional shaking and titrated the excess $\mathrm{KOH}$ with the $0.5 \mathrm{M}$ hydrochloric acid solution. The iodine value (IV) was determined by the method describe in American Oil Chemist's Society. To determine IV, titrating the mixture of tested fuel and chemical reagents against $0.01 \mathrm{~N}$ sodium thiosulfate solution until the disappearance of the blue color. IV was calculated by the following Eq. 1:

Iodine value $=(B-S) \times N \times 0.001269 / W$ 1

Where, $\mathrm{S}$ and $\mathrm{B}$ are the amounts (in unit of $\mathrm{mL}$ ) of sodium thiosulfate solution required for titration of the tested sample and blank sample respectively. $\mathrm{N}$ is the molar concentration (in unit of $\mathrm{mol} / \mathrm{L}$ ) of sodium thiosulfate solution and $\mathrm{W}$ is the weight (in unit of $\mathrm{gm}$ ) of the tested sample.

Physical properties such as moisture content, density and calorific value of the oil were determined by following ASTM D 1744 (Karl Fisher method), ASTM D 1480/81 and ASTM D 240 respectively. Viscosity, flash point, pour point and cloud point were determined by standards ASTM D 445, ASTM D 93 (Pensky-Martens Flashpoint Apparatus, Lazer Scientific Inc., Germany), ASTM D 2500 and ASTM D 97 respectively.

\section{RESULT AND DISCUSSION}

\subsection{Characterization of Oil}

Oil was extracted from the seed by mechanical press method. The oil content of Pitraj oil was found as 33.3\% (wt/wt). Physical properties of the oil were measured by standard method and presented in Table 1.

Table 1. Physical properties of raw oil

\begin{tabular}{|l|c|}
\hline Property name & Value \\
\hline Color & Dark green \\
\hline Specific gravity & 0.92 \\
\hline Viscosity at $25^{\circ} \mathrm{C}\left(\mathrm{mm}^{2} / \mathrm{sec}\right)$ & 53.7 \\
\hline$\%$ FFA & 7.5 \\
\hline Saponification value & 233.4 \\
\hline Oil content $(\mathrm{wt} / \mathrm{wt})$ & $33.3 \%$ \\
\hline
\end{tabular}

\subsection{Preparation of Biodiesel}

Biodiesel was prepared from higher FFA containing pithraj oil by two-step methods. The first step is acid catalyzed esterification followed by base catalyzed transesterification. 
3.2.1 First step - Esterification: Acid catalyzed esterification reaction was carried out to reduce the FFA content of raw oil below $2 \mathrm{wt} \%$ to make the transesterification reaction feasible in the second step. Various parameters that affect the esterification reaction are oil to methanol molar ratio, catalyst concentration, reaction, temperature and time. All the reaction parameters were optimized and the results are discussed below.

Since esterification is a reversible reaction higher molar ratio of alcohol results in a greater ester conversion in a shorter time. The esterification reaction was studied at oil to methanol molar ratio of 1:3 and 1:6 and the results are represented in Fig. 1.

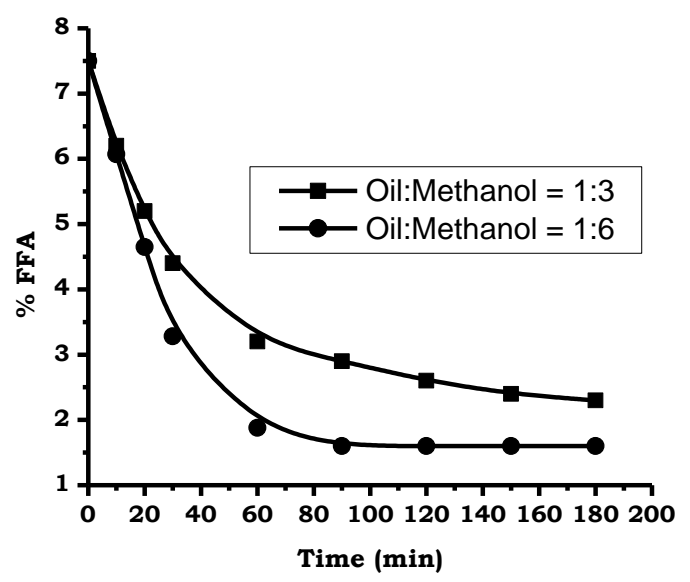

Fig. 1: Effect of oil to methanol molar ratio on esterification reaction.

From Fig. 1 it is observed at a molar ratio of 1:3 the maximum reduction in FFA was $2.3 \%$ from $7.5 \%$ within $3 \mathrm{hr}$ whereas at 1:6 molar ratios it was reduced to $1.6 \%$ within $1.5 \mathrm{hr}$. Reduction of FFA below $2 \%$ occurs within $1 \mathrm{hr}$ at the oil to methanol molar ratio of 1:6. The reaction was carried out at a catalyst $\left(\mathrm{H}_{2} \mathrm{SO}_{4}\right)$ concentration of $5 \mathrm{wt} \%$ of oil and a temperature of $70^{\circ} \mathrm{C}$.

Sulfuric acid was used as catalyst to enhance the rate of esterification reaction. The reaction was carried out at three different catalyst concentrations and the results are represented in the Fig. 2.

From Fig. 2 it was observed that rate of the reaction increases as the concentration of catalyst increased. With a higher concentration of catalyst it requires less time to reach the reaction in equilibrium. It requires $1 \mathrm{hr}$ for the reduction of FFA below $2 \%$. Reactions were conducted at oil to methanol molar ratio of 1:6 with a temperature of $70^{\circ} \mathrm{C}$.

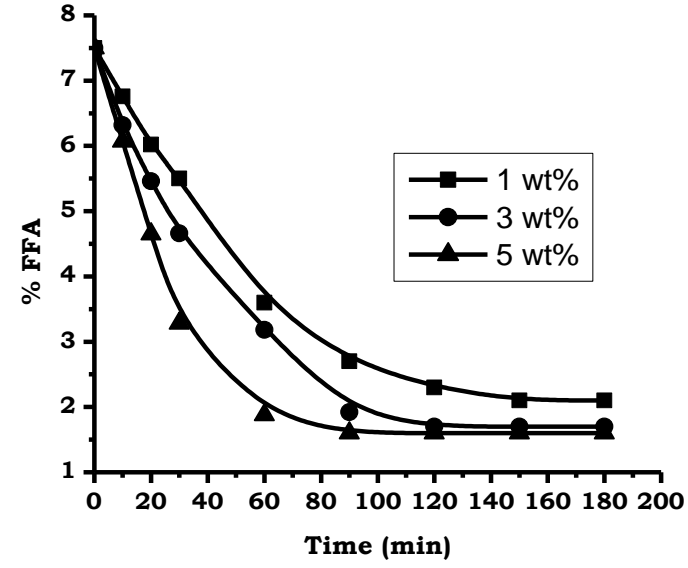

Fig. 2: Effect of catalyst concentration on esterification reaction.

Temperature is an important parameter that affects the esterification reaction. There is an increase in the rate of reaction with the increase in temperature. The reaction was carried out at five different temperatures with 1:6 oil to methanol molar ratio and a catalyst concentration of 5 wt $\%$ of oil. The results are represented in the Fig. 3.

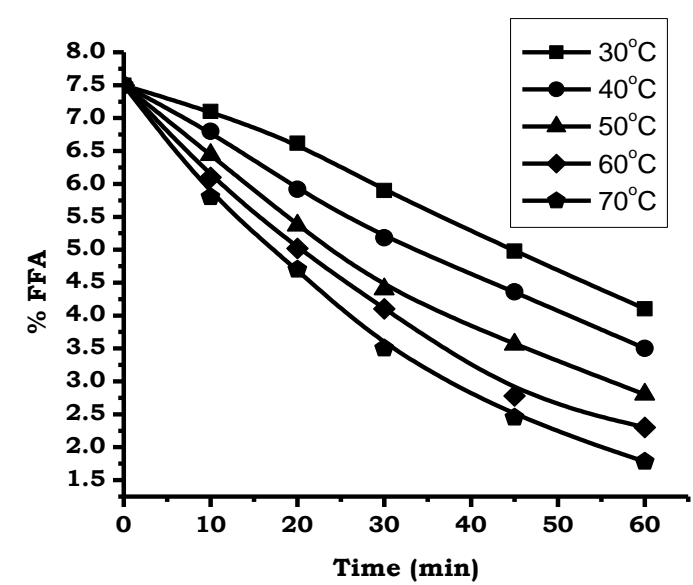

Fig. 3: Effect of temperature on esterification reaction.

From Fig. 3 it was observed that the maximum reduction of FFA occurs within $1 \mathrm{hr}$ at a temperature of $70^{\circ} \mathrm{C}$ which was considered as our optimum temperature for esterification reaction.

\subsubsection{Second step - Transesterification:}

After the first step (acid catalyzed esterification) the FFA of the pithraj oil reduces from $7.5 \%$ to $1.6 \%$ but the change in viscosity was little, from $53.7 \mathrm{~mm}^{2} / \mathrm{s}$ to 35.7 $\mathrm{mm}^{2} / \mathrm{s}$. To reduce the viscosity, the product of esterification was subjected to base catalyzed transesterification reaction. Various reaction parameters such as oil to methanol molar ratio, catalyst concentration and reaction temperature were optimized. Results are presented in the following figures. 


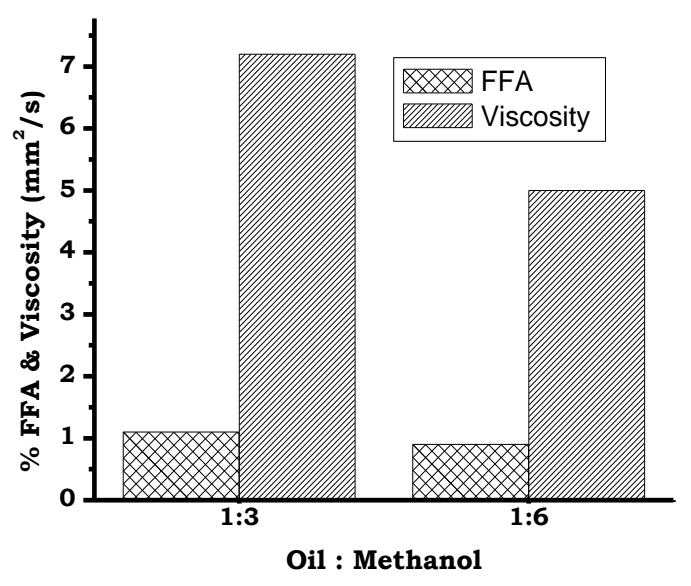

Fig. 4: Effect of methanol molar ratio on transesterification reaction.

From Fig. 4 it is observed at a molar ratio of 1:3 the maximum reduction in viscosity was $7.2 \mathrm{~mm}^{2} / \mathrm{sec}$ from $35.7 \mathrm{~mm}^{2} / \mathrm{sec}$ within $1 \mathrm{hr}$ whereas at $1: 6$ molar ratio it was reduced to $5.01 \mathrm{~mm}^{2} / \mathrm{sec}$. The reaction was carried out at a catalyst $(\mathrm{NaOH})$ concentration of $1 \mathrm{wt} \%$ of oil and a temperature of $60^{\circ} \mathrm{C}$.

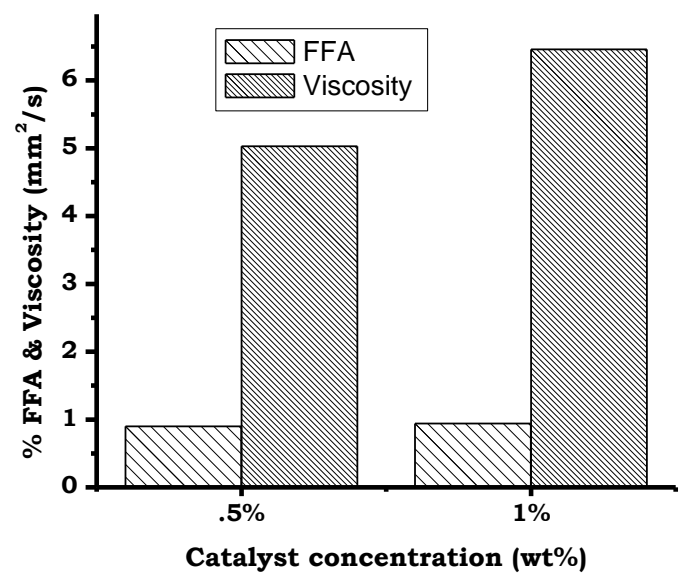

Fig. 5: Effect of catalyst concentration on transesterification reaction.

Transesterification reaction was carried out at two different catalyst concentrations and results are represented in the Fig. 5. Sodium hydroxide was used as catalyst. From Fig. 5 it was observed that lower concentration of catalyst yields better result. With a higher concentration of catalyst FFA reacts with sodium hydroxide and produce soap. This soap again converts to FFA during acid wash of biodiesel, which results a slight increase in viscosity. But, the catalyst concentration less than $0.5 \mathrm{wt} \%$ was not effective for transesterification reaction. Reactions were conducted at oil to methanol molar ratio of $1: 6$ for $1 \mathrm{hr}$ with a temperature of $60^{\circ} \mathrm{C}$.

Transesterification reaction was carried out at four different temperatures with 1:6 oil to methanol molar ratio and a catalyst concentration of $1 \mathrm{wt} \%$ of oil. The results are represented in the Fig. 6. From Fig. 6 it was observed that the maximum reduction in viscosity occurs at a temperature of $60^{\circ} \mathrm{C}$ which was considered as our optimum temperature for transesterification reaction.

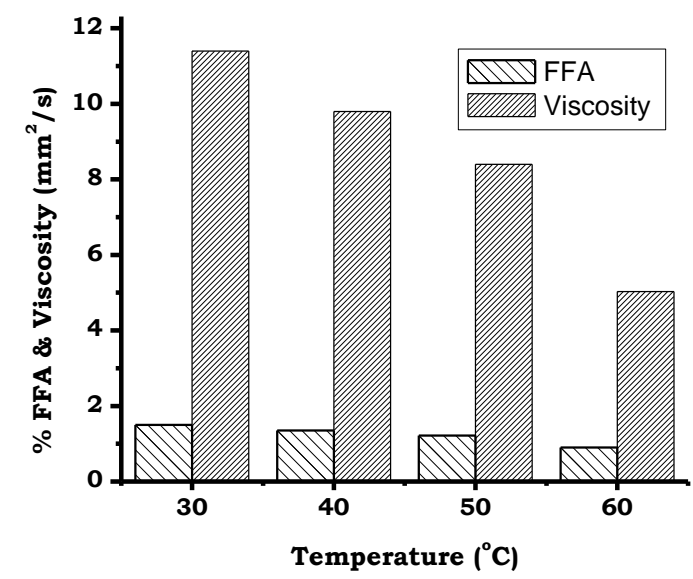

Fig. 6: Effect of temperature on transesterification reaction.

\subsection{Characterization of Biodiesel}

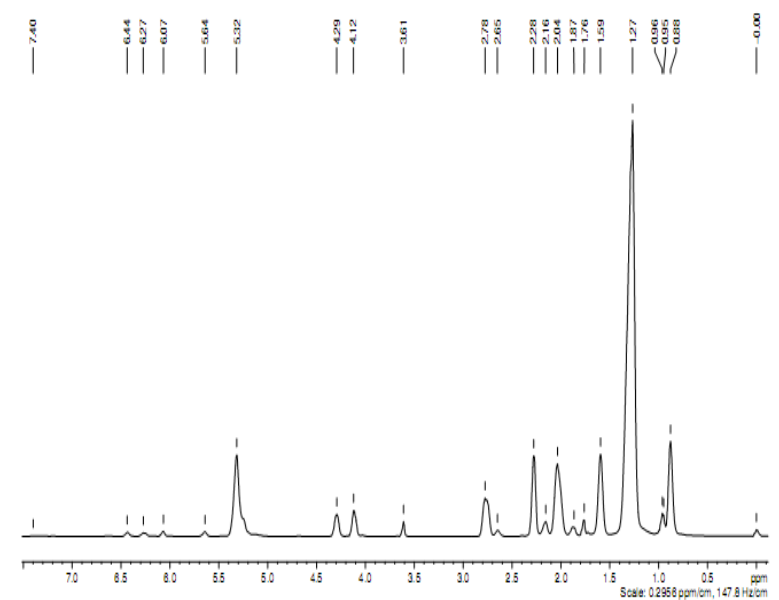

Fig. 7(a): ${ }^{1} \mathrm{H}$ NMR of Pithraj Oil.

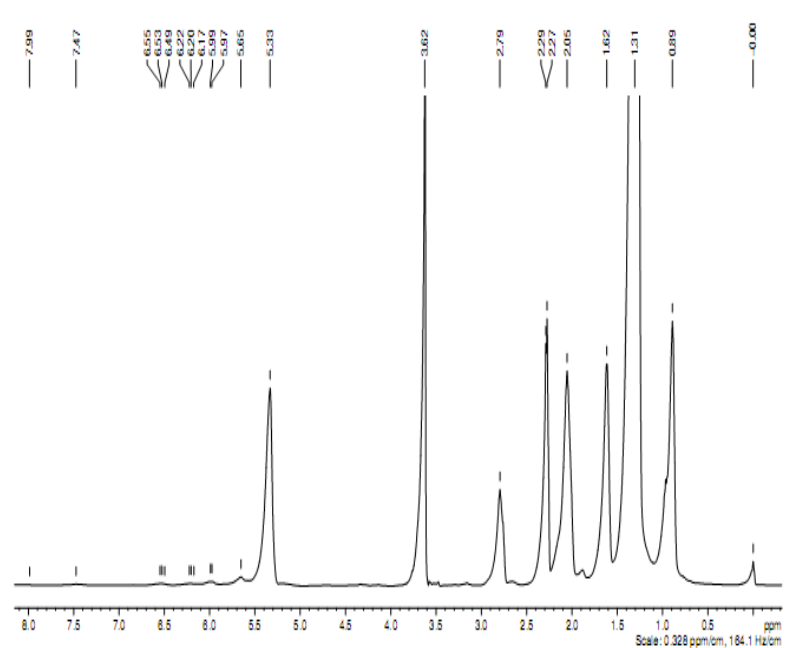

Fig. 7(b): ${ }^{1} \mathrm{H}$ NMR of Pithraj Oil Biodiesel. 
${ }^{1} \mathrm{H}$ NMR spectroscopy of biodiesel and Pithraj oil is done to investigate the presence of triglyceride backbone in the sample. Fig. $7 \mathrm{a}$ and $\mathrm{b}$ depicts the ${ }^{1} \mathrm{H}$ NMR spectrum of the Pithraj oil and biodiesel from Pithraj oil in the region of $0-11.5 \mathrm{ppm}$. Glyceride protons of triglycerides are assigned in the range of 4 $4.5 \mathrm{ppm}$. The protons of the methyl ester moiety and the a-carbonyl methylene groups are assigned at approximately $3.7 \mathrm{ppm}$ and $2.3 \mathrm{ppm}$ respectively [10]. It can be seen that the glyceride backbone of triglyceride is totally absent in the biodiesel sample.

The important properties of pithraj oil methyl esters are compared with biodiesel and petro-diesel standards $[11,12]$ and presented in Table 2. Most of the physicochemical properties of rubber seed oil methyl ester are comparable to those of biodiesel standard and petrodiesel. The two-step process significantly reduced the viscosity and acid value of the oil

Table 2. Properties of pithraj oil biodiesel

\begin{tabular}{|c|c|c|c|}
\hline Properties & $\begin{array}{c}\text { Pithraj oil } \\
\text { methyl } \\
\text { ester }\end{array}$ & $\begin{array}{c}\text { Biodiesel } \\
\text { standard }\end{array}$ & $\begin{array}{c}\text { Diesel } \\
\text { standard }\end{array}$ \\
\hline Color & Reddish & - & - \\
\hline $\begin{array}{c}\text { Specific gravity } \\
\text { at } 25^{0} \mathrm{C}\end{array}$ & 0.88 & $\begin{array}{c}0.88 \text { (at } \\
\left.15.5^{\circ} \mathrm{C}\right)\end{array}$ & $\begin{array}{c}0.85 \text { (at } \\
\left.15.5^{\circ} \mathrm{C}\right)\end{array}$ \\
\hline $\begin{array}{c}\text { Viscosity }\left(\mathrm{mm}^{2} / \mathrm{s}\right. \\
\left.\text { at } 25^{\circ} \mathrm{C}\right)\end{array}$ & 4.2 & $1.9-6.0$ & $1.3-4.1$ \\
\hline FFA Weight\% & 0.82 & Trace & - \\
\hline $\begin{array}{c}\text { Saponification } \\
\text { value } \\
\text { (mg of KOH/gm } \\
\text { of oil) }\end{array}$ & 212.3 & - & - \\
\hline Iodiene value & 74.5 & - & - \\
\hline Cetane Index & 55.3 & - & 42 \\
\hline $\begin{array}{c}\text { Calorific } \\
\text { Value(Mj/Kg) }\end{array}$ & 36.2 & 37.5 & 60 to 80 \\
\hline Flash point $\left({ }^{0} \mathrm{C}\right)$ & 150 & 100 to 170 & -15 to 5 \\
\hline Cloud point $\left({ }^{0} \mathrm{C}\right)$ & 3 & -3 to 12 & -35 to - \\
\hline Pour point $\left({ }^{0} \mathrm{C}\right)$ & 0 & -15 to 10 \\
\hline
\end{tabular}

\section{CONCLUSION}

Biodiesel was prepared from pithraj oil by two-step method. In the first step (acid catalyzed esterification) the reduction of FFA occurs to the desired content but the viscosity of the oil does not reduce to the desired level. That's why a second step (base catalyzed transesterification) requires for the reduction of viscosity. Reaction parameters for esterification and transesterification reaction were optimized and are listed in the Table 3. It can be concluding that pithraj oil is very much suitable for biodiesel production in our country and it can contribute to meet the energy demand.
Table 3. Optimum reaction parameters

\begin{tabular}{|c|c|c|}
\hline Parameters & Esterification & Transesterification \\
\hline Oil : Methanol & $1: 6$ & $1: 6$ \\
\hline Catalyst conc. & $5 \mathrm{wt} \% \mathrm{H}_{2} \mathrm{SO}_{4}$ & $0.5 \mathrm{wt} \% \mathrm{NaOH}$ \\
\hline Temperature & $70^{\circ} \mathrm{C}$ & $60^{\circ} \mathrm{C}$ \\
\hline Time & $1.5 \mathrm{hr}$ & $1 \mathrm{hr}$ \\
\hline
\end{tabular}

\section{ACKNOWLEDGEMENT}

The authors express their deep gratitude to the University Grant Commission (UGC) for financial support to conduct this research.

\section{REFERENCES}

[1] Vicente, G., Martinez, M. and Aracil, J. (2004) Integrated biodiesel production: A comparison of different homogeneous catalysts systems, Bioresour. Technol., 92: 297-305.

[2] Encinar, J.M., Gonzalez, J.F. and RodriguezReinares, A. (2005), Biodiesel from used frying oil. Variables affecting the yields and characteristics of the biodiesel, Ind. Eng. Chem. Res., 44: 5491-5499.

[3] Antolin, G., Tinaut, F.V., Briceno, Y., Castano, V., Perez, C. and Ramrez, A.I. (2002), Optimization of biodiesel production by sunflower oil transesterification, Bioresour. Technol., 83: 111114.

[4] Murayama, T., Fujiwara, Y. and Noto, T. (2000), Evaluating waste vegetable oils as a diesel fuel, J. Automobile Eng. 214: 141-148.

[5] Knothe, G. (2002), Curr. Perspect. Biodiesel Inform, 13: 900-903.

[6] Kaul A.K. and Das M.L. (2011), Promoting the conservation and use of underutilized and neglected crops, Ministry of Agriculture, Dhaka.

[7] Wang Y., Ou S., Liu P. and Zhang Z. (2007) Preparation of biodiesel fromwaste cooking oil via two-step catalyzed process, Energy Conversion and Management, 48: 184-188.

[8] Meher L.C., Naik M., Naik S.N. and Das L.M. (2008), Production of biodiesel from high free fatty acid Karanja (Pongamia pinnata) oil, Biomass and Bioenergy, 32: 354-357.

[9] Jeffery, G.H., Bassett, J., Mendham, J. and Denney, R.C. (1991), Vogel's textbook of quantitative chemical analysis, $5^{\text {th }}$ edition, UK: Longman Scientific and Technical, pp. 308-309.

[10] Knothe G. (2000), Monitoring a progressing transesterification reaction by fiber-optic near infrared spectroscopy with correlation to ${ }^{1} \mathrm{H}$ nuclear magnetic resonance spectroscopy. J Am Oil Chem Soc, 77(5):489-93.

[11] Leung D.Y.C., Xuan Wu and Leung M.K.H. (2010), A review on biodiesel production using catalyzed transesterification, Applied Energy, 87:1083-95.

[12] Joshi R.M. and Pegg M.J. (2007), Flow properties of biodiesel fuel blends at low temperatures, Fuel, 86:143-151. 